\title{
The Behaviour of Frozen Scoria in Unconfined Compression Test
}

\author{
Yanyan Agustian
}

Widyatama University, Indonesia

Copyright $\mathrm{C} 2019$ by authors, all rights reserved. Authors agree that this article remains permanently open access under the terms of the Creative Commons Attribution License 4.0 International License

\begin{abstract}
The mechanical behaviour of the frozen or partially frozen soil changes significantly as soon as the ice holds the soil particles together. The strength of frozen soil can increase significantly. However, due to the temperature dependency and viscose nature of ice, the strength of frozen soils changes with time, strain rate and temperature. Water migration towards the ice lenses occurs during the freezing process depending on the characteristics of the soil, i.e. grain size and mineralogy, resulting in a significant change of the soil structure. Frost heaving may be the result, induced by the expansion of the water as it changes phase from frozen state. The aim of this study is to determine the unconfined compressive strength to calculate the unconsolidated shear strength of the frozen scoria under unconfined conditions. In unconfined compression tests, the influence of dry density $\rho_{\mathrm{d}}$ and water content $w$ to the unconfined compression behaviour of frozen scoria was observed. The compressive strength of frozen scoria increases with the increase of $w$ as well as the increase of $\rho_{\mathrm{d}}$ and the compressive strain of frozen scoria $\varepsilon_{\mathrm{f}}$ (axial strain at failure) is dependent on $\rho_{\mathrm{d} .}$. Although some data scatters appear caused by the inhomogeneous of the samples, the effects of $w$ and $\rho_{\mathrm{d}}$ to the stiffness of frozen scoria were observed. As well as initial Young's modulus $E_{0}$, secant modulus $E_{50}$ of frozen scoria increases with the increasing of $w$ and $\rho_{\mathrm{d}}$.
\end{abstract}

Keywords Scoria, Yukishiro, Stress-strain, Deformation Characteristics, Frozen

\section{Introduction}

The strength and stiffness properties of the soils are the most important groupings, which presents the engineering properties of the soils. Understanding of the characteristics in the strength and the stiffness is fundamental to the derivation and implementation of realistic constitutive numerical model. Soil strength is defined as the maximum load that a soil may sustain until or just before it fails. One of the recognized strength parameters is unconfined compressive strength $q_{\mathrm{u}}$, measured from unconfined compression test. The stiffness of the soil determines the amount of deformation that it may display under load. The main recognized stiffness properties of soil are Young's modulus $(E)$, Poisson's ratio, bulk modulus and shear modulus $(G)$.

Natural and artificial frozen soils have been widely studied for decades [1][2][3][4]. The behaviour of scoria in triaxial tests has been studied both in monotonic[5] and cyclic[6] to observe its mechanical behaviour.

Three stages that should be experienced on the frozen soils stress-strain loads according to the studying method on material stress-strain behaviour in material mechanics; they are: (1) elastic stage; strain increases linearly with the increase of stress; (2) strain hardening stage; in this stage the plastic deformation is dominating over the specimen deformation and the elastic deformation is relatively subordinate status and (3) yield stage or flow stage; in this stage the peak is followed by a decrease of the deviator stress upon continued deformation. Frozen scoria, in this study, was tested in confined compression to establish the effects of dry density and water content on its mechanical behaviour. In the present work, by using the Young's modulus, which represents the stiffness of the studied frozen scoria, the resistance to deformation of the reconstituted frozen scoria was investigated through unconfined compression experimental program.

The influences of water content on compressive strength of frozen sands have been investigated [7]. They proposed a new experimental equation in order to clarify the influence of water content on the compressive strength of frozen sands. They concluded that as the water content increase, the compressive strength decreases under constant degree of saturation and water content, which gives the maximum compressive strength, can be quantitatively determined by employing the dry specific gravity in densest state. 


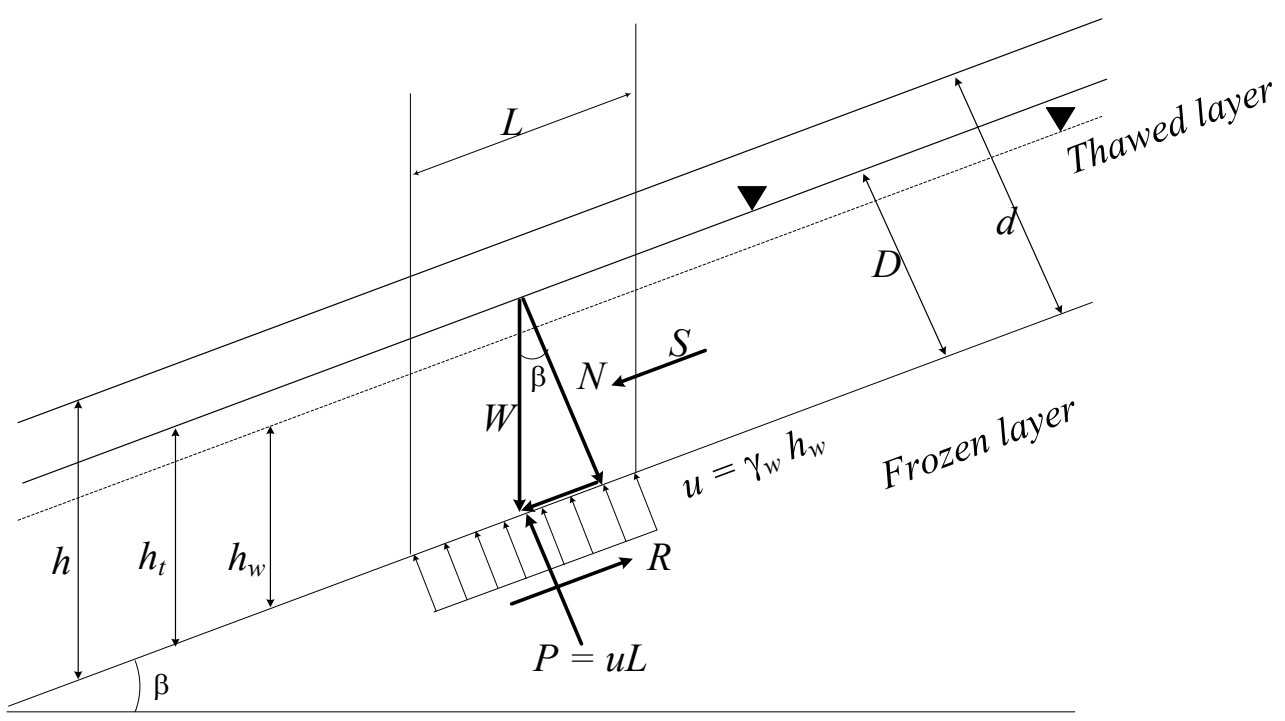

Figure 1. The simplified stress balance in snow layer where the Yukishiro occurs (modified from Anma, 2007)

"Yukishiro" is one of slope failure phenomenon involved scoria in frozen condition. Yukishiro can be illustrated as a large quantity of water result from snow melting by the sudden rise of temperature and rain water can cause surplus water in the snow layer and if the layer does not absorb this abundant water then it will make the layer become saturated and the water accumulated. The water of the sloping snow layer then begins to drift to the down slope, and driving force begins to push down the snow layer. If the height of the water level and the angle of inclination of the slope become big, then the osmotic pressure grows. If this osmotic pressure exceeds than the resisting force to support the snow layer then the slope will lose in stability, and the snow layer begins to slide.

The stress balance in snow layer, thawed scoria, and frozen bed with water pressure can be simplified as shown by Figure. 1[8]. Driving force $T$, resisting force $R$ and safety factor are defined as

$$
\begin{gathered}
T=W \sin \beta+S \\
R=(N-P) \tan \phi=(W \cos \beta-P) \tan \phi \\
F S=R / T
\end{gathered}
$$

Where:

$$
\begin{gathered}
W=\gamma \times h \cos \phi \\
P=\left(\gamma_{w} \times h_{w}\right) L
\end{gathered}
$$

$S$ is osmotic pressure $\left(\mathrm{KN} / \mathrm{m}^{3}\right)$

$\beta$ is slope angle $\left({ }^{\circ}\right)$

$\gamma_{w}$ is the unit weight of soil layer

${ }_{w}$ is unit weight of water

$\varphi$ is angle of internal friction of soil layer (scoria)

\section{Method Analyses}

The primary purpose of this test is to determine the unconfined compressive strength. According to the JIS standard, the unconfined compressive strength $\left(q_{\mathrm{u}}\right)$ is defined as the compressive stress at which an unconfined cylindrical specimen of soil will fail in a simple compression test. In addition, in this test method, the unconfined compressive strength is taken as the maximum load attained per unit area, or the load per unit area at $15 \%$ axial strain, whichever occurs first during the performance of a test.

The schematic diagram and the setting up of the test apparatus are shown by Figure 2. Cylindrical specimens with nominal measurements of $50 \mathrm{~mm}$ in diameter and 100 $\mathrm{mm}$ in length were prepared by packing a split copper mold. It was originally desirable for the size of the specimen to be a diameter of $100 \mathrm{~mm}$ and $200 \mathrm{~mm}$ in height. The reason is that by examining such a large specimen with $100 \mathrm{~mm}$ in diameter, the maximum particle size that allowed to keep the ratio between specimen diameter to the maximum particle size above five is $19.00 \mathrm{~mm}$, so that the particle size is large and good enough to represent the original filed condition. However, in case of frozen soils, such kind of large specimens will have a large compressive strength and at least up to $20 \mathrm{kN}$ of stress is needed to be applied for loading to have the specimens fail. These conditions are hard to fulfill in our laboratory.

Scoria was poured into a mould such a way by using a pipe so that the pluviation height was controlled depend on the length of the pipe. To have a denser sample, the mould was tapped with a wooden mallet 100 times only for 1.50 $\mathrm{g} / \mathrm{cm}^{3}$ of dry density target. Amount of water as shown by Table 5.2 then was poured to the sample and the samples were then cured with curing time based on targeted dry density and water content. In order to have a homogeneous distribution of temperatures, the specimens were then kept in freezer for almost 24 hours in the range of -3 to $0^{\circ} \mathrm{C}$. The specimens then were subjected to unconfined compression tests with $1 \% / \mathrm{min}$. of constant axial strain rate. The axial 
deformation was automatically measured by external dial gauge and the data were collected by a computer continually as well as the axial load.

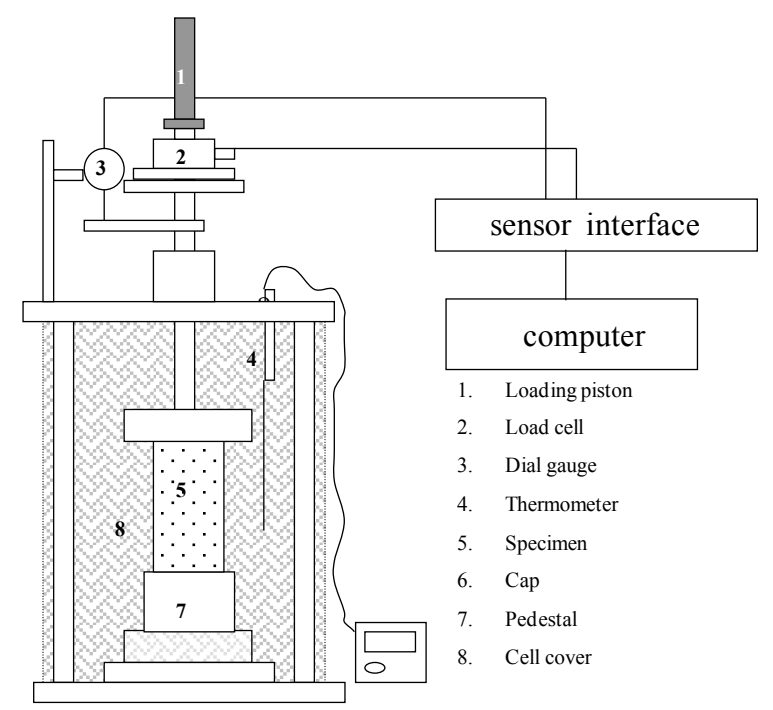

Figure 2. Schematic diagram of unconfined compression test

The displacement and compression stress data recorded by the computer during loading were then used to calculate the compression strain $\varepsilon(\%)$, unconfined compression strength $q_{\mathrm{u}}\left(\mathrm{MN} / \mathrm{m}^{2}\right)$, axial strain at failure $\varepsilon_{\mathrm{f}}(\%)$ and Young's modulus $\left(E_{0}\right.$ and $\left.E_{50}\right)$. Below are equations expressed those calculations.

$$
\begin{aligned}
& \varepsilon=\frac{\Delta H}{H_{0}} \times 100 \\
& \begin{array}{cc}
\varepsilon & : \text { axial strain }(\%) \\
\Delta H & : \text { deformation }(\mathrm{cm}) \\
& : \text { initial height }(\mathrm{cm})
\end{array} \\
& \begin{array}{c}
H_{0} \sigma=\frac{P}{A_{0}} \times\left(1-\frac{\varepsilon}{100}\right) \times 10 \\
\begin{array}{|c|c|}
\hline \sigma & : \text { compression stress }(\mathrm{KN} / \mathrm{m} 2) \\
\hline P & : \text { loading }(\mathrm{N}) \\
\hline A_{0} & : \text { initial sample area }(\mathrm{cm} 2) \\
\hline
\end{array}
\end{array}
\end{aligned}
$$

\section{Results}

All specimens were prepared by using air pluviation method. By accomplishing the pluviation height, a desired range of dry density could be achieved (Table1). A preliminary examination was carried out to evaluate the result of each high pluviation and then desired dry densities were decided. Results from filed investigations and laboratory tests show that the original field water content was range from $8.70 \%$ to $26.54 \%$. Three series of sample water contents were targeted based on this field scoria dry density: $14 \%, 17 \%$ and $20 \%$.
Table 1. Method to achieve targeted dry density of the scoria samples

\begin{tabular}{|c|c|c|c|}
\hline $\begin{array}{c}\text { Density Target } \\
\left(\mathrm{g} / \mathrm{cm}^{3}\right)\end{array}$ & $\begin{array}{c}\text { Weight of scoria } \\
(\mathrm{g})\end{array}$ & $\begin{array}{c}\text { Pluviation height } \\
(\mathrm{cm})\end{array}$ & $\begin{array}{c}\text { Amount of tapping } \\
\text { (times) }\end{array}$ \\
\hline 1.25 & 300 & 10 & 0 \\
\hline 1.35 & 700 & 90 & 0 \\
\hline 1.50 & 700 & 90 & 100 \\
\hline
\end{tabular}

It was difficult to have a homogeneous sample in term of water content distribution for reconstituted frozen sample. Unsatisfactorily test results appear in the strength characteristics if the water content distribution of the sample is not constant, although the samples are made in the same condition. To evaluate the homogeneity of water content, samples were cut into three pieces: upper, middle and lower layer and then the water content of each layer was measured for the preliminary investigation (Figure 3). The evaluation was conducted for each water contents targeted and the result is shown in Table 2 .

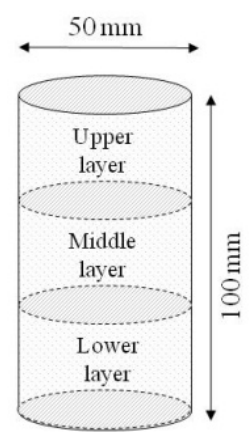

Figure 3. Samples were cut into three pieces: upper, middle and lower layers, to evaluate the distribution of water content

Table 2. Water content target and water that used for each targeted dry density

\begin{tabular}{|c|c|c|c|}
\hline $\begin{array}{c}\text { Water content } w \\
\text { target }(\%)\end{array}$ & $\begin{array}{c}\text { Water used for } 1.25 \\
\mathrm{~g} / \mathrm{cm}^{3} \text { of dry density } \\
\text { target }(\mathrm{g})\end{array}$ & $\begin{array}{c}\text { Water used for } 1.35 \\
\mathrm{~g} / \mathrm{cm}^{3} \text { of dry density } \\
\text { target }(\mathrm{g})\end{array}$ & $\begin{array}{c}\text { Water used for } 1.50 \\
\mathrm{~g} / \mathrm{cm}^{3} \text { of dry density } \\
\text { target }(\mathrm{g})\end{array}$ \\
\hline 14 & 35 & 40 & 50 \\
\hline 17 & 45 & 50 & 60 \\
\hline 20 & 55 & 60 & 70 \\
\hline
\end{tabular}

Scoria was poured into a mould such a way by using a pipe so that the pluviation height was controlled depend on the length of the pipe. To have a denser sample, the mould was tapped with a wooden mallet 100 times only for 1.50 $\mathrm{g} / \mathrm{cm}^{3}$ of dry density target. Amount of water then was poured to the sample and the samples were then cured with curing time based on targeted dry density and water content (Table 3). In order to have a homogeneous distribution of temperatures, the specimens were then kept in freezer for almost 24 hours in the range of -3 to $0^{\circ} \mathrm{C}$. The specimens then were subjected to unconfined compression tests with $1 \% /$ min. of constant axial strain rate. The axial deformation was automatically measured by external dial gauge and the data were collected by a computer continually as well as the axial load. 
Table 3. Water content measurement results from sample cut evaluation

\begin{tabular}{|c|c|c|c|}
\hline \multirow{2}{*}{$\begin{array}{c}\text { Water } \\
\text { content } w \\
\text { target (\%) }\end{array}$} & $\begin{array}{c}\text { Curing time } \\
\text { (minute) }\end{array}$ & Layer & $\begin{array}{c}\text { Water } \\
\text { content } w \\
(\%)\end{array}$ \\
\hline \multirow{2}{*}{14} & \multirow{2}{*}{100} & upper & 10.27 \\
\cline { 3 - 4 } & & middle & 13.96 \\
\cline { 3 - 4 } & \multirow{2}{*}{17} & lower & 11.78 \\
\hline \multirow{2}{*}{70} & upper & 16.12 \\
\cline { 3 - 4 } & \multirow{2}{*}{20} & middle & 17.52 \\
\cline { 3 - 4 } & \multirow{2}{*}{40} & lower & 16.01 \\
\hline \multirow{2}{*}{4} & upper & 19.23 \\
\cline { 3 - 4 } & \multirow{2}{*}{} & middle & 20.31 \\
\hline \multirow{2}{*}{} & & lower & 19.31 \\
\hline
\end{tabular}

\subsection{Stress-strain Characteristics}

In this sub-chapter, the influence of dry density and water content to stress-strain relationships is explained based on curves provided from unconfined compression tests. Two specimens which have a similar dry density and water content of each series were conducted to evaluate the reproducibility of the tests. Table 4 is the resume of test conditions and some results.
The following may be drawn from the stress-strain curves results from the tests:

There is not so much different in the stress-strain relations between the two tests of each series. Except D, F and I of test codes, all the test results show quite good result in term of stress-strain relationships. The large difference results of some tests were due to inconsistency of the specimen conditions i.e. the targeted water content and dry density.

All specimens experienced the three stages that common as usually shown by normal sands at frozen state: (1) elastic stage; strain increases linearly with the increase of stress; (2) strain hardening stage; in this stage the plastic deformation is dominating over the specimen deformation and the elastic deformation is relatively subordinate status and (3) yield stage or flow stage. Loose samples exhibit the stress-strain curves increase continuously after strain hardening stage is reached as shown by Figure 4(a) and a limit state or peak stress is not obtained for some samples. It could be argued that after a sufficient strain the peak would, probably, be reached. However, this can be achieved due to the limited range of visible deformation.

Both dry density and water content are the important factors affecting stress-strain relations on frozen scoria as shown by Figure 4 and 5. A large difference between two range dry densities is shown by Figure 5, especially for $1.50 \mathrm{~g} / \mathrm{cm}^{3}$ of dry density.

Table 4. Resume of test conditions and some of the result

\begin{tabular}{|c|c|c|c|c|c|c|c|c|}
\hline (1) & (2) & (3) & (4) & (5) & (6) & (7) & (8) & (9) \\
\hline Test code & & $\begin{array}{l}m \\
(\mathrm{~g})\end{array}$ & $\begin{array}{l}w \\
(\%)\end{array}$ & $\begin{array}{c}\rho_{\mathrm{d}} \\
(\mathrm{g} / \mathrm{cm} 3)\end{array}$ & $\begin{array}{c}q_{\mathrm{u}} \\
\left(\mathrm{MN} / \mathrm{m}^{2}\right)\end{array}$ & $\begin{array}{l}\varepsilon_{\mathrm{f}} \\
(\%)\end{array}$ & $\begin{array}{c}E_{0} \\
\left(\mathrm{MN} / \mathrm{m}^{2}\right)\end{array}$ & $\begin{array}{c}E_{50} \\
\left(\mathrm{MN} / \mathrm{m}^{2}\right)\end{array}$ \\
\hline A1 & \multirow{6}{*}{ loose } & 299.81 & 13.38 & 1.205 & 3.64 & 11.55 & 65.88 & 56.22 \\
\hline A2 & & 302.12 & 14.58 & 1.211 & 3.64 & 10.11 & 103.53 & 79.76 \\
\hline B1 & & 314.37 & 17.31 & 1.283 & 5.03 & 13.69 & 137.11 & 106.30 \\
\hline B2 & & 310.28 & 17.13 & 1.266 & 4.83 & 12.77 & 131.74 & 111.39 \\
\hline $\mathrm{C} 1$ & & 317.61 & 20.77 & 1.255 & 5.81 & 10.67 & 214.93 & 201.49 \\
\hline $\mathrm{C} 2$ & & 325.35 & 20.62 & 1.291 & 6.12 & 12.90 & 203.02 & 153.04 \\
\hline D1 & \multirow{6}{*}{ moderate } & 317.32 & 13.91 & 1.364 & 4.93 & 10.10 & 124.72 & 105.09 \\
\hline D2 & & 305.03 & 13.09 & 1.320 & 3.94 & 9.12 & 109.03 & 92.18 \\
\hline E1 & & 318.08 & 16.86 & 1.341 & 5.29 & 11.56 & 126.94 & 106.57 \\
\hline E2 & & 322.95 & 16.41 & 1.360 & 5.92 & 12.50 & 119.90 & 98.85 \\
\hline F1 & & 334.31 & 19.30 & 1.386 & 6.69 & 12.18 & 173.63 & 142.90 \\
\hline $\mathrm{F} 2$ & & 330.55 & 19.92 & 1.362 & 6.65 & 11.37 & 201.18 & 176.34 \\
\hline G1 & \multirow{6}{*}{ dense } & 352.33 & 14.67 & 1.510 & 8.68 & 8.37 & 222.99 & 207.11 \\
\hline $\mathrm{G} 2$ & & 352.16 & 14.62 & 1.507 & 8.48 & 8.07 & 252.30 & 236.23 \\
\hline $\mathrm{H} 1$ & & 374.13 & 17.12 & 1.542 & 10.61 & 8.95 & 242.80 & 221.93 \\
\hline $\mathrm{H} 2$ & & 369.22 & 17.45 & 1.552 & 10.90 & 9.31 & 269.45 & 260.47 \\
\hline I1 & & 371.60 & 19.96 & 1.536 & 11.88 & 7.38 & 454.92 & 459.13 \\
\hline $\mathrm{I} 2$ & & 374.59 & 19.61 & 1.553 & 12.73 & 8.61 & 404.32 & 409.28 \\
\hline
\end{tabular}

NOTE: (3) weight; (4) water content; (5) dry density; (6) unconfined compressive strength; (7) axial strain at failure; (8) initial Young's modulus; (9) secant Young's modulus 

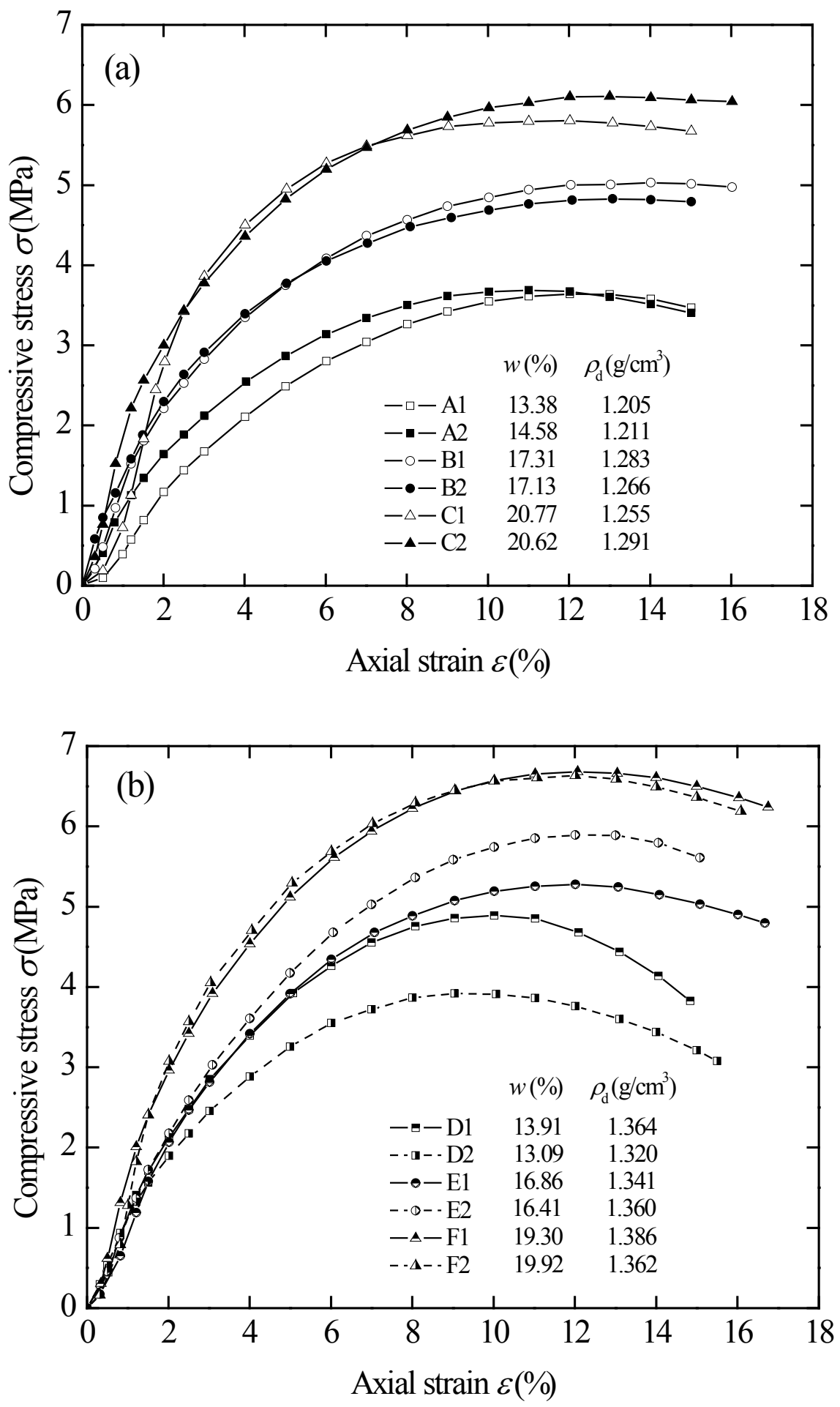


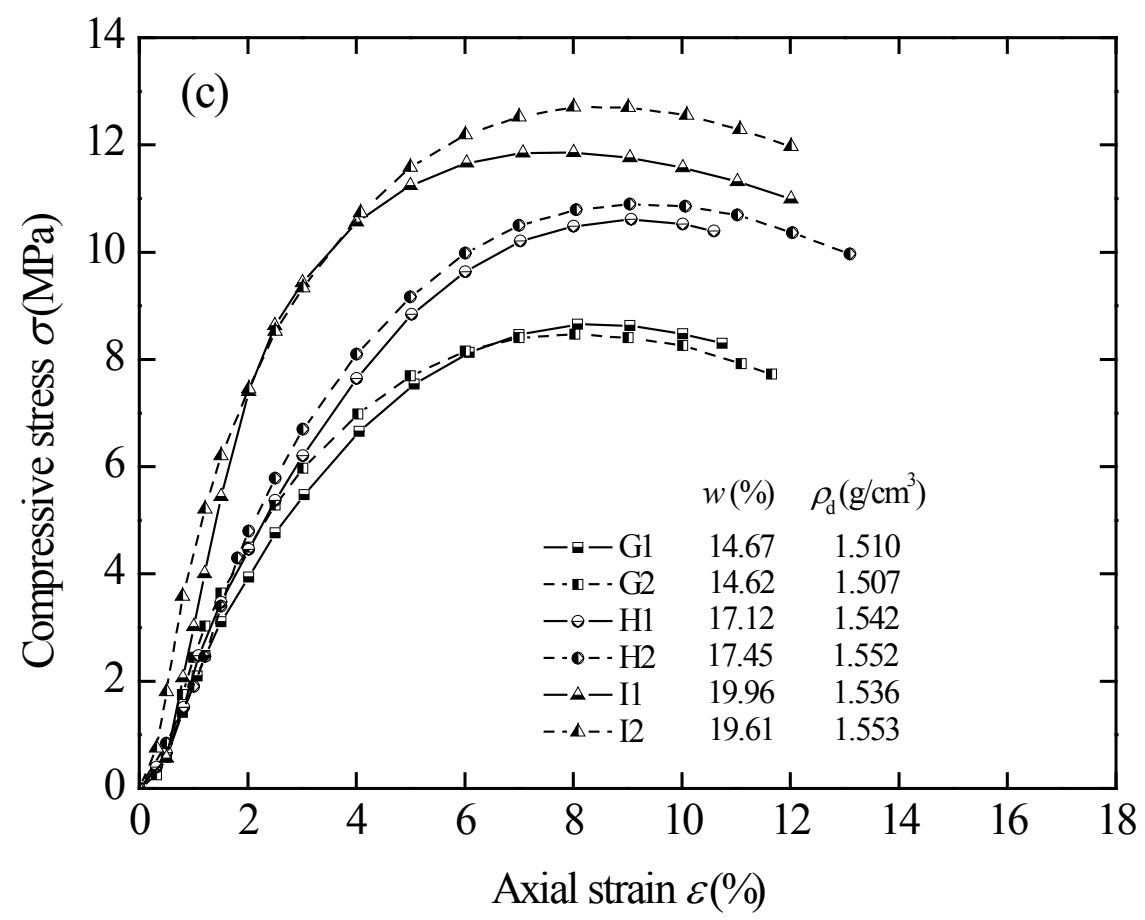

Figure 4. The effects of water content on the stress-strain relations (a) loose samples, (b) moderate samples and (c) dense samples.

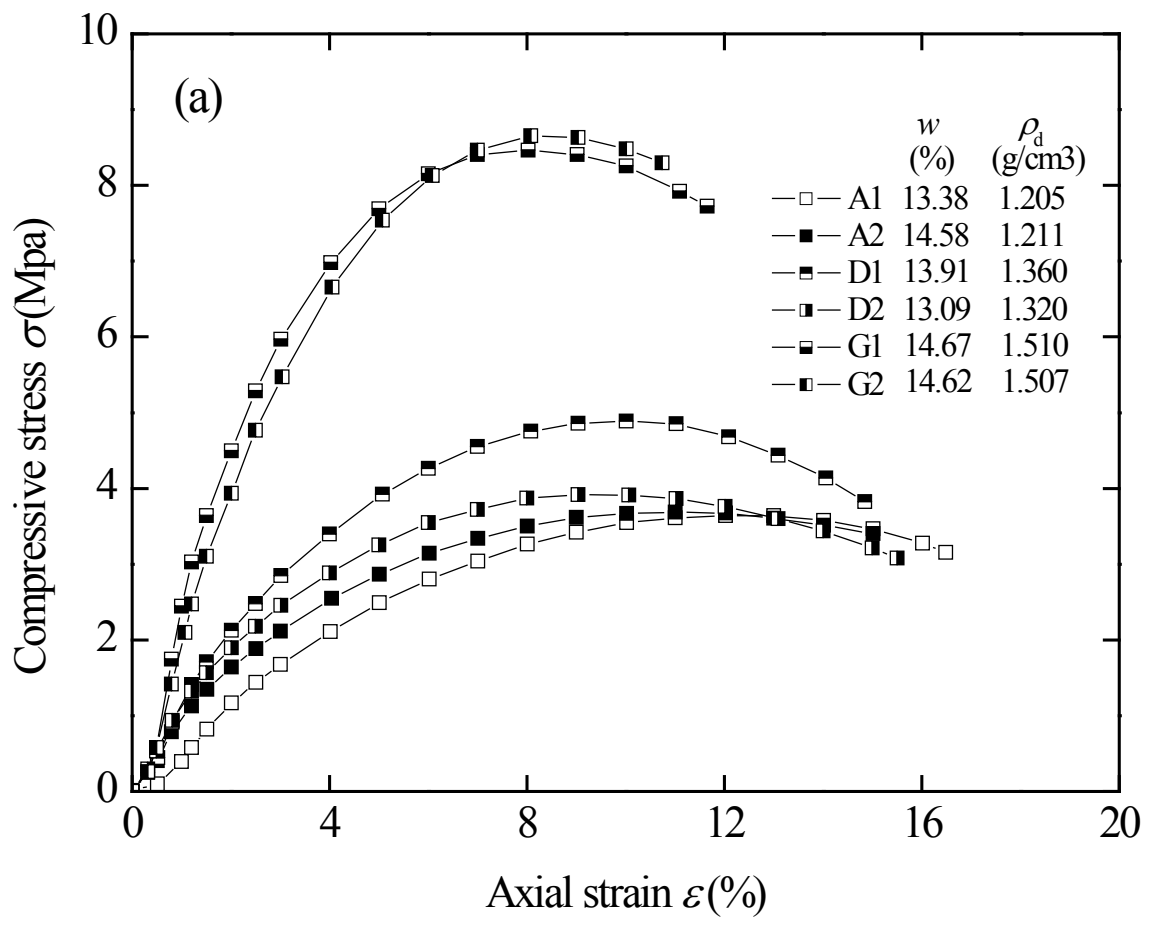



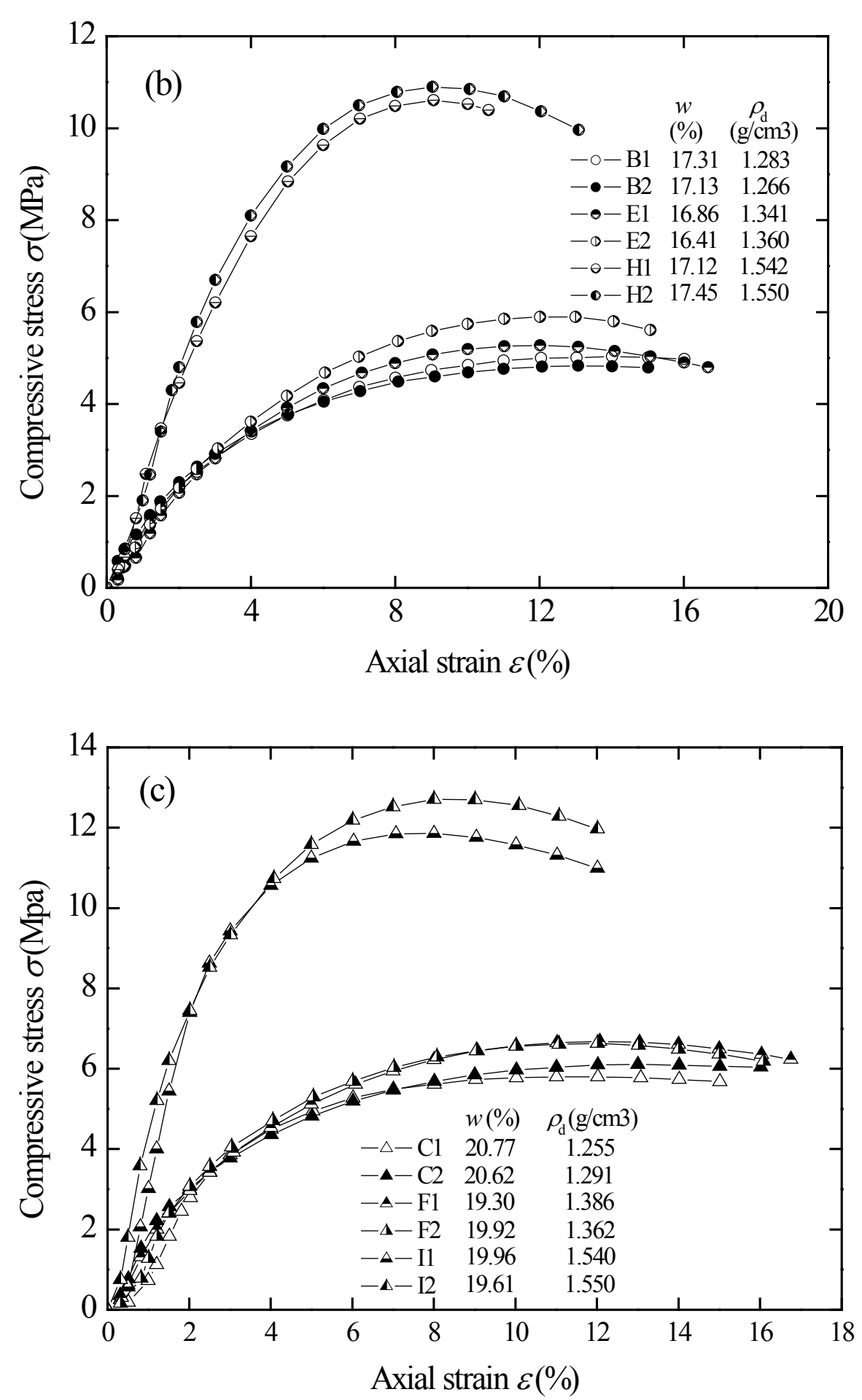

Figure 5. The effects of dry density on the stress-strain relations: (a) $14 \%$ targeted water content, (b) $17 \%$ targeted water content and (c) $20 \%$ targeted water content.

\subsection{Relationships between Unconfined Compression Strength, Dry Density and Water Content}

To characterize the unconfined strength of frozen scoria, the influences of dry density and water content on unconfined compression strength were evaluated and the results were plotted as shown by in Figure 6(a) and 6(b). It can be seen from Figure 6(a) that the compressive strength of frozen scoria increases with the increasing in dry density. Based on the results, the relationship between dry density and compression strength is not a simple proportion relation. In other words, it is not a linear relationship. Based on the results of the relationships between the unconfined compression strength and the dry density, the 
best-fit lines drawn through the plotted points appear to approach parabolic values. It can be assumed that for all various water contents, the unconfined compression strength does not change so much at range $1.25 \sim 1.35 \mathrm{~g} / \mathrm{cm}^{3}$ of dry density, while larger than $1.50 \mathrm{~g} / \mathrm{cm}^{3}$ give a larger unconfined compression strength.

Figure 6(b) shows that unconfined strength of frozen scoria is also dependent on water content. Furthermore, it shows that the proportion coefficient of unconfined compression strength-water content relations of target dry density $1.50 \mathrm{~g} / \mathrm{cm}^{3}$ is larger than two others proportion coefficients and is tied to consideration of Figure 5(a). This property could be explained by the increasing on water content that would make increase the particle bonding force and particle interlocking and increase the unconfined compression strength consequently.
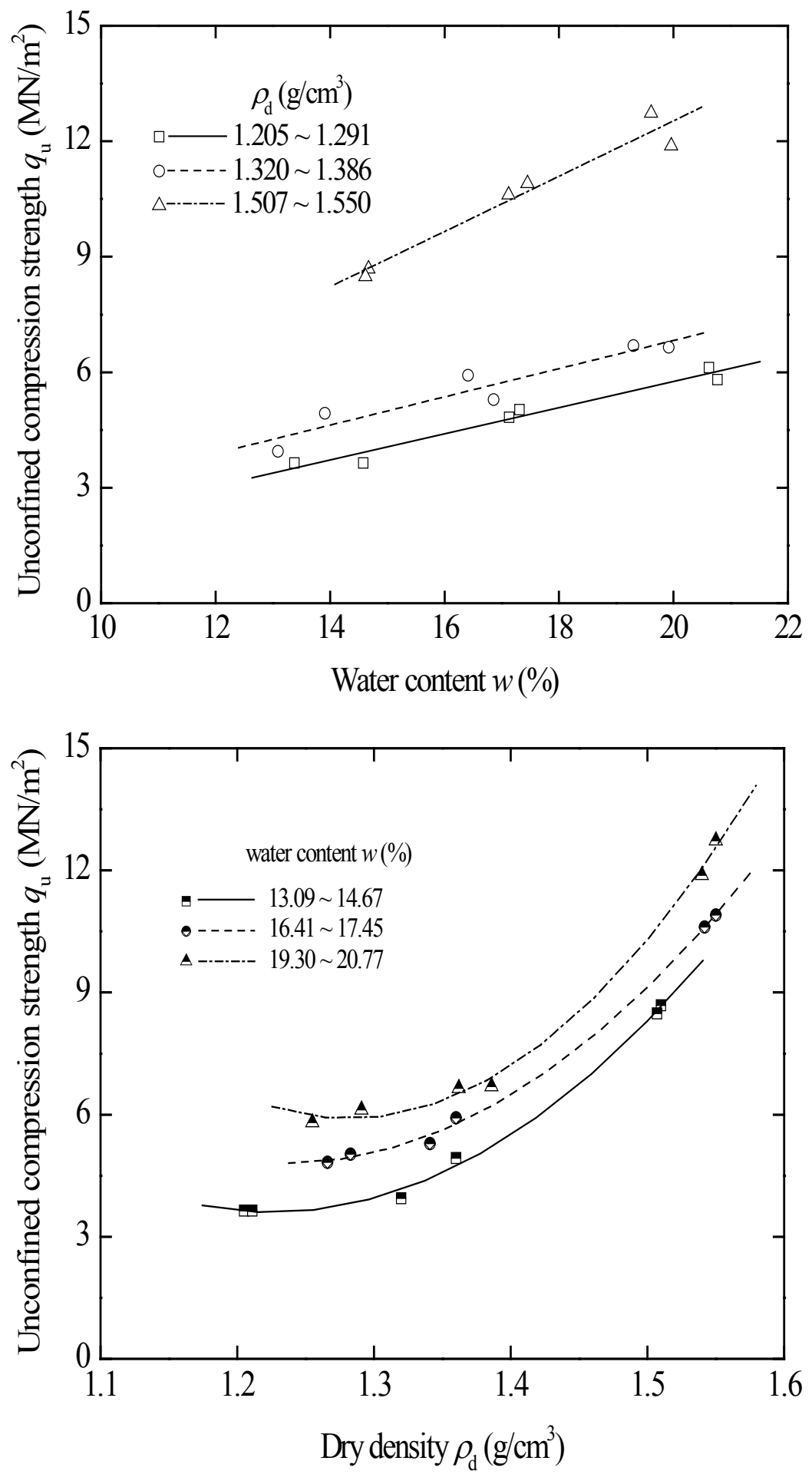

Figure 6. (a) Effects of water content on unconfined com0pression strength and dry density relation and (b ) Effects of dry density on unconfined compression strength and water content relation 
Three phases of soils generally consist of water, soil and air, which their relationships can be expressed as follows:

$$
\begin{gathered}
w=S_{\mathrm{r}} G_{\mathrm{w}}\left(\frac{1}{G_{\mathrm{d}}}-\frac{1}{G_{\mathrm{s}}}\right) \\
G_{\mathrm{d}}=\frac{1}{\left(\frac{w}{S_{\mathrm{r}} G_{\mathrm{w}}}+\frac{1}{G_{\mathrm{s}}}\right)} \\
S_{\mathrm{r}}=\frac{w}{G_{\mathrm{w}}\left(\frac{1}{G_{\mathrm{d}}}-\frac{1}{G_{\mathrm{s}}}\right)}
\end{gathered}
$$

where Gw is the specific gravity of water and Gs is the specific gravity of soil particles. In order to evaluate the influence of the water content and dry density, the physical parameter such as $\mathrm{Gd}$ and $\mathrm{Sr}$ have been taken into account. The compressive strength qu is a function of water content $\mathrm{w}$ and the dry specific gravity $\mathrm{Gd}$, as follows [7]:

$$
q_{\mathrm{u}}=q^{*}\left(\frac{w}{100}\right)^{m} G_{\mathrm{d}}{ }^{\mathrm{n}}
$$

Where $q^{*}, m$ and $n$ are constants. In order to estimate these constants, both sides of the Eq. (9) are taken as logarithm.

$$
\log q_{\mathrm{u}}=\log q^{*}+m \log (w / 100)+n \log G_{\mathrm{d}}
$$

Because Eq. (10) is a linear model, the least square method was used to define the value of $q^{*}$. Calculation results of $q^{*}, m$ and $n$ constants from frozen scoria for each series tested are shown by Table 5 . The suitability of Eq (9) is shown in Figure 7, from which a linear relation between $q_{\mathrm{u}}$ and $(w / 100)^{\mathrm{m}} G_{\mathrm{d}}{ }^{\mathrm{n}}$ can be inferred. The values of constant $q^{*}$ is directly derived from this plot as the fit linear of the relations.

To see the relationships between unconfined compression strength $q_{\mathrm{u}}, w$ and $G_{\mathrm{d}}, q_{\mathrm{u}}$ obtained from test results have been plotted against $(w / 100)^{\mathrm{m}} G_{\mathrm{d}}{ }^{\mathrm{n}}$ as shown in Figure 7 and are compared to Toyoura sand [7]. The figure shows that there is no a large difference both in unconfined compression strength and in the value of $(w / 100)^{\mathrm{m}} G_{\mathrm{d}}{ }^{\mathrm{n}}$ or loose and moderate samples. This may be due to similarity in water content and the dry density itself between the loose and moderate. On the other hand, unconfined compression strength and the value of $(w / 100)^{\mathrm{m}} G_{\mathrm{d}}{ }^{\mathrm{n}}$ are larger for the dense samples.

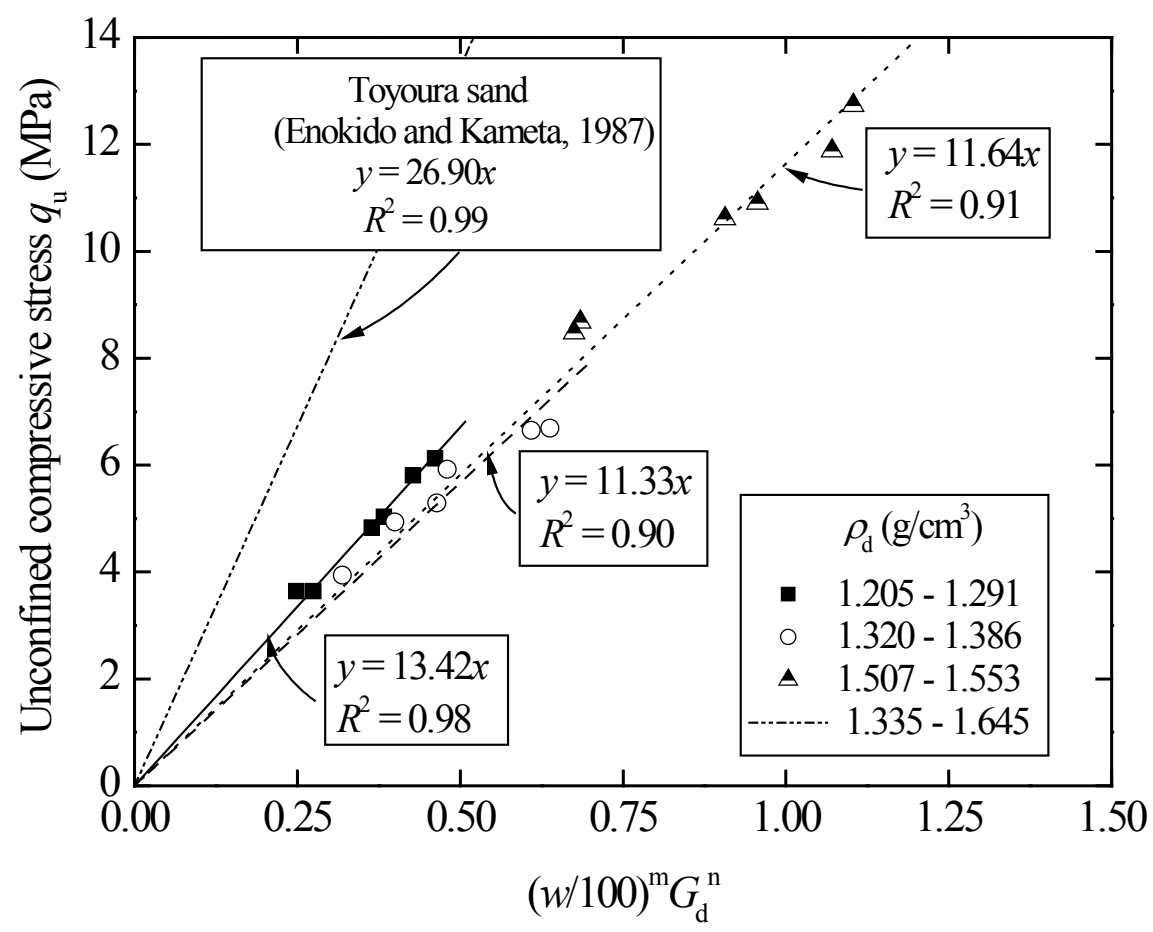

Figure 7. Relation between $q_{\mathrm{u}}$ and $(w / 100)^{\mathrm{m}} G_{\mathrm{d}}{ }^{\mathrm{n}}$ of scoria tested and compared to Toyoura sand [7]. 
It is seen clearly the correlation among unconfined strength, water content and dry density by employing Figure 7 through the validity of Eq. 9, more than only from stress-strain relationships plotting. Since the dry density is roughly constant for all series (loose, moderate and dense samples), the attention is to be paid to each series at unconfined compression strength dependency on water content. All frozen scoria samples tested exhibit proportional in unconfined compression strength to the water content, that is, the increasing in water content is followed by increasing in unconfined compression strength and resulting the constant $q^{*}$ roughly similar. The multiple correlation coefficient of the linear model of the scoria tested is about 0.97, which means the equation applied for scoria is accurate. The figure also shows that frozen scoria lied below the Toyoura sand, both in $q_{\mathrm{u}}$ and contant $q^{*}$. This may be due to Toyoura sand tested on the region of lower temperature $\left(-30^{\circ} \mathrm{C}\right)$ and the tests conducted in high controlled stress $(200-300 \mathrm{kPa} / \mathrm{sec})$ while the present scoria tested on $-3-0^{\circ} \mathrm{C}$ and the tests was held on strain controlled with strain increment $1 \% / \mathrm{min}$.

Table 5 is the calculation results that shows the constants $m$ are roughly similar, $m=1$ (Toyoura sand, $m=0.852$ ), the constant $n$ is proportional to the dry density and constant $q^{*}$ obtained from fit linear from the plot of relationship between $q_{\mathrm{u}}$ and $(w / 100)^{\mathrm{m}} G_{\mathrm{d}}{ }^{\mathrm{n}}$ is not so much different for all series at different densities.

Table 5. Calculation results of $m, \mathrm{n}$ and $\mathrm{q}^{*}$ constants

\begin{tabular}{|c|c|c|c|}
\hline$\rho_{\mathrm{d}}\left(\mathrm{g} / \mathrm{cm}^{3}\right)$ & $m$ & $n$ & $q^{*}(\mathrm{Mpa})$ \\
\hline $1.205-1.291$ & 0.96 & 2.92 & 13.42 \\
\hline $1.320-1.386$ & 1.20 & 4.66 & 11.33 \\
\hline $1.507-1.553$ & 0.96 & 9.37 & 11.64 \\
\hline
\end{tabular}

\subsection{Deformation Characteristics}

Deformation characteristic is an important thing in the study on the mechanical behaviour of soils. Researchers usually relate the deformation characteristics of a soil with its failure characteristics, Young's modulus, deformation behaviour seen by visual inspection and so on. In this study these evaluations are described in order to have a general description about the frozen scoria deformation characteristics on unconfined compression test.

Figure 8 (a) shows the relationships between the axial strain at failure $\varepsilon_{\mathrm{f}}$ and the dry density $\rho_{\mathrm{d}}$. While some scatters appear from the test results, the plots show that opposite proportion of dry density to the axial strain at failure. Higher value of $\rho_{\mathrm{d}}$ gave the lower value of $\varepsilon_{\mathrm{f}}$, which means that the denser scoria sample remains faster to failure in certain axial strain. This is a common deformation characteristic of soils tested in triaxial compression test as well as scoria in dry state. The effect of water content on the axial strain at failure is shown by Figure 8(b). While the effect of dry density on the axial strain at failure $\varepsilon_{\mathrm{f}}$ - water content $w$ relationships is seen, the plots also shows that about $17 \%$ of water content gave the value of $\varepsilon_{\mathrm{f}}$ at peak for all various $\rho_{\mathrm{d}}$.

The stiffness properties of scoria were quantified in terms of initial Young's modulus $\left(E_{0}\right)$ and secant Young's modulus $\left(E_{50}\right)$. It has been known that denser sample has a higher stiffness for almost kind of soils. Frozen scoria has experienced the same manner as shown by Figure 9 and Figure 10. However, the evaluation of deformation through $E_{0}$ and $E_{50}$ in the present study is not so satisfy, since scatters appear from the results. This is due to the homogeneity of frozen scoria at the upper and lower part was not achieved perfectly and then caused some samples deformed locally at the upper and lower part immediately after the test was started. Consequently, this influenced the stress-strain relationships at the initial stage and made it hard to obtained satisfactorily data to evaluate the initial Young's modulus.

Initial Young's modulus is defined as the gradient of linear portion of stress-strain curve starting from the origin and modulus deformation is defined as the gradient of the straight line through the origin and stress-strain curve corresponding to a half of $q_{\mathrm{u}}$. The effects of $w$ and $\rho_{\mathrm{d}}$ to the stiffness of frozen scoria were observed. As well as initial Young's modulus $E_{0}$, secant Young's modulus $E_{50}$ of frozen scoria increase with the increasing of $w$ and $\rho_{\mathrm{d}}$. The effects of inhomogeneous in water content on the deformation mode of the samples can be seen from photo 1 that the sample exhibit deformation only at the upper part while in the middle part exhibit undeformed. 

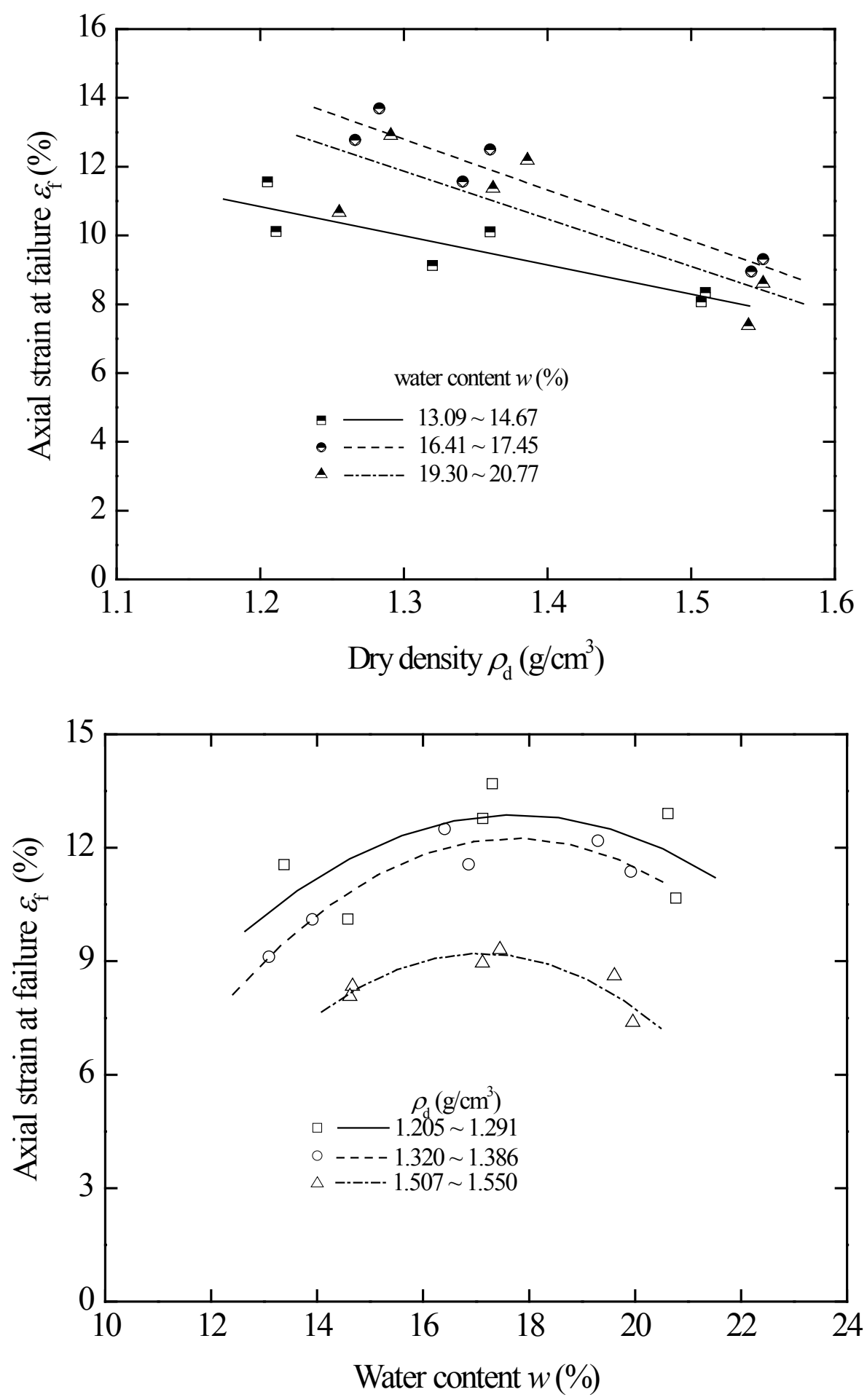

Figure 8. (a) Axial strain at failure and dry density relation and (b) axial strain at failure and water content relation 

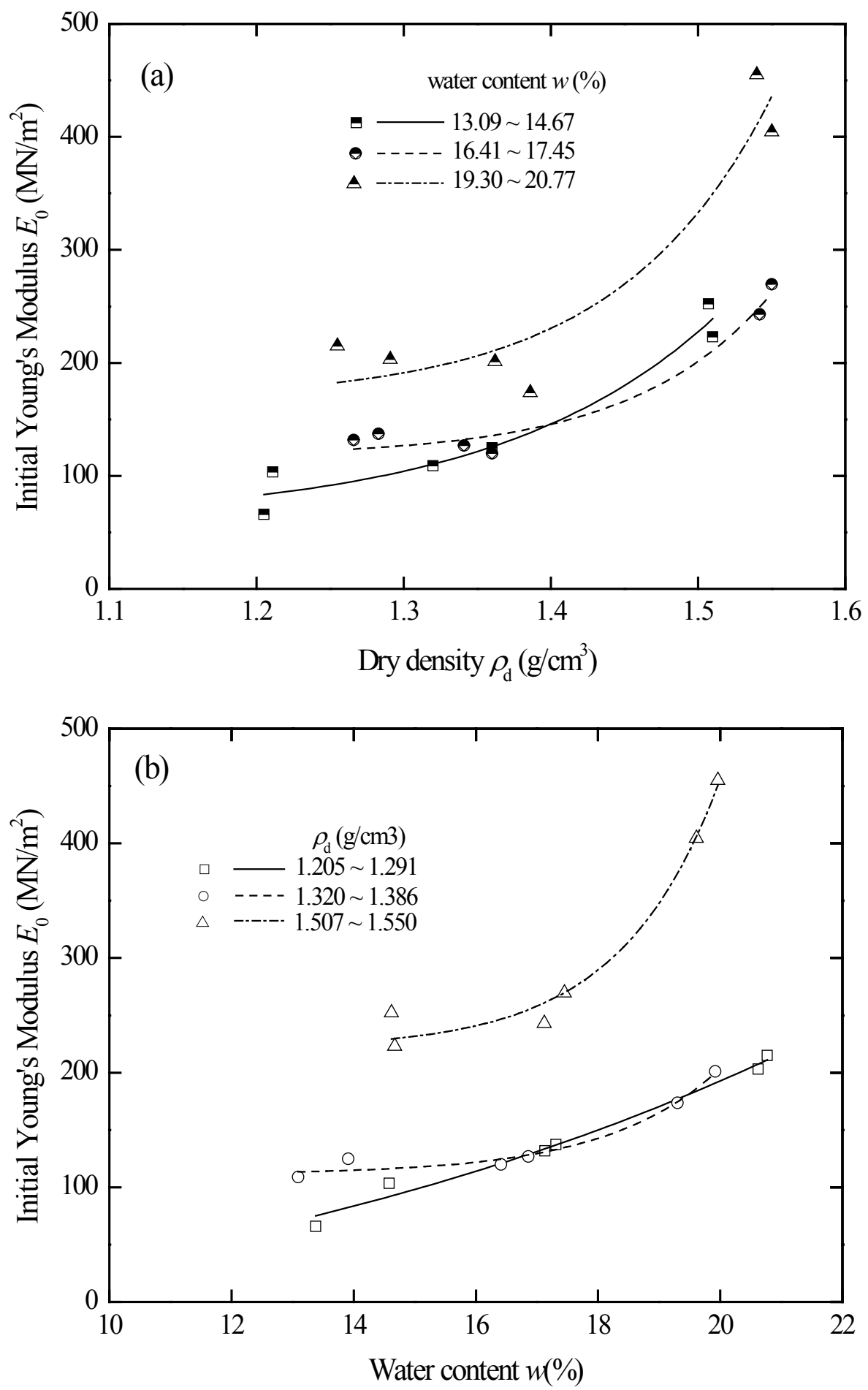

Figure 9. (a) Initial Young's modulus and dry density relation and (b) Initial Young's modulus and water content relation 

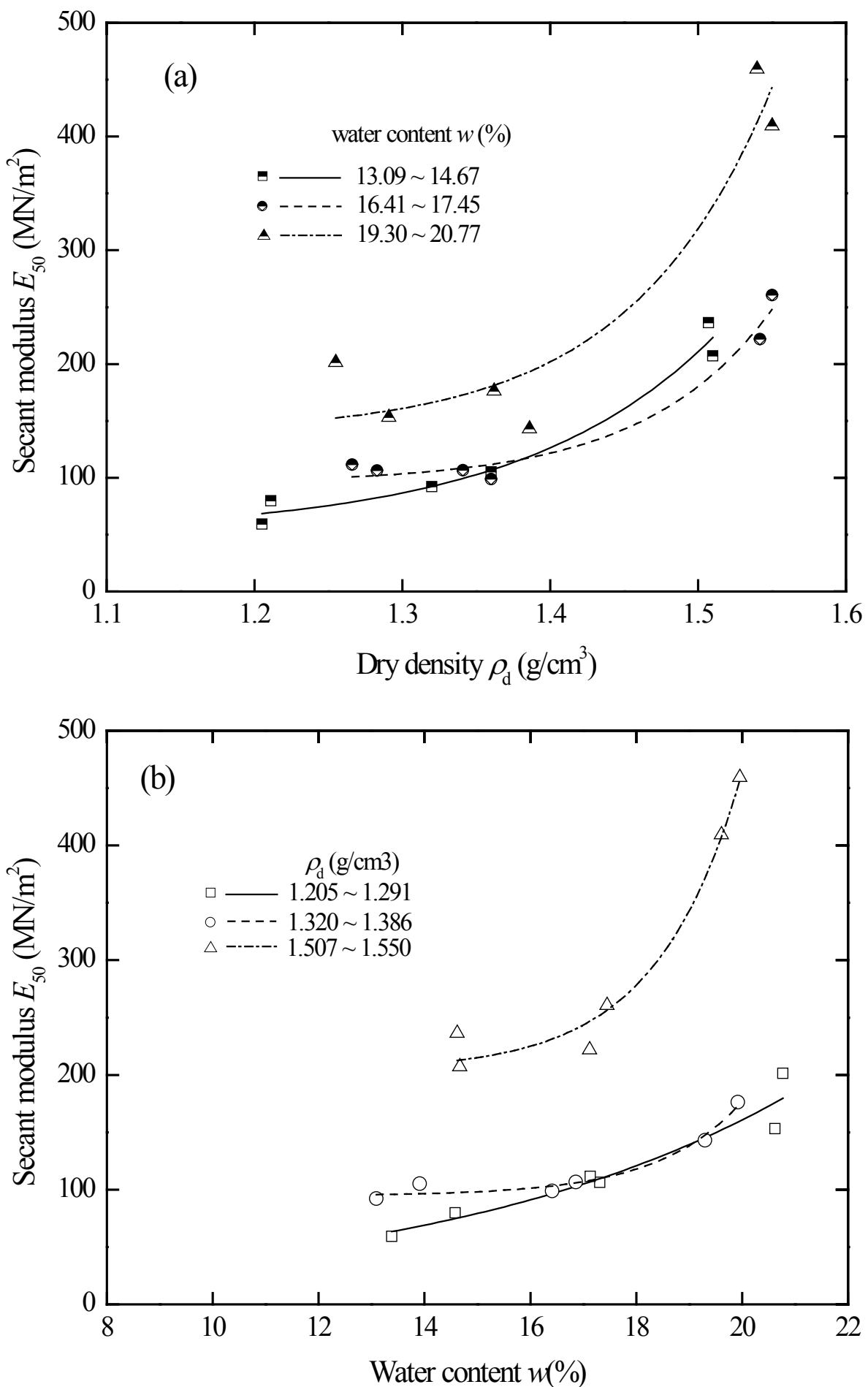

Figure 10. (a) Secant modulus and dry density relation and (b) Secant modulus and water content relation 


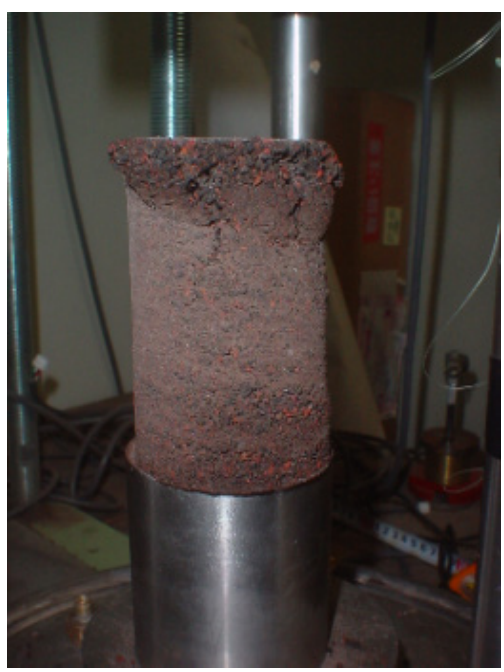

Photo 1. The example of unhomogeneous in water content distribution; deformed only in the upper part

\subsection{Engineering Practices}

The compressive strength of frozen soil is practically important in geotechnical construction engineering, which employs artificial freezing and low temperature structures, etc. It is especially used to calculate the strength of walls of frozen soil. This strength is affected by many factors including loading rate, water content, dry specific gravity and the degree of saturation. In order to meet the needs of construction in cold regions and the application of artificial ground freezing such as mine shaft and tunnel construction, the strength characteristics and the stress-strain behaviour of the frozen soils have to be studied.

There are many case histories of landslides reported in cold regions. It is necessary to pay attention to slope instability during a project construction and geo-environmental protection. In the cold region, the instability of frozen soil slopes have been classified into collapse, creep slope, debris flow, vegetation layer creeping slope and thawing slumping. Among them both of debris flow and vegetation layer creeping slope are the kind of failure of the active layer. It is closely related to engineering and hazardous to the environment, vegetation and engineering project.

\section{Conclusions}

On the basis of the number of tests in the present study, the influence of dry density and water content to the unconfined compression behaviour of frozen scoria was observed $[9,10]$.

(1) The method of unconfined compression test for frozen scoria has been developed.

(2) The compressive strength of frozen scoria increase with the increase of water content $\mathrm{w}$ as well as the increase of dry density $\rho_{\mathrm{d}}$ and the compressive strain of frozen scoria (axial strain at failure) is dependent on $\rho_{\mathrm{d}}$. The increasing of $\rho_{\mathrm{d}}$ is followed by the decrease value of $\varepsilon_{\mathrm{f}}$. The $\varepsilon_{\mathrm{f}}$-W relationship shows that about $17 \%$ of water content gave the value of $\varepsilon_{\mathrm{f}}$ at peak for all various $\rho_{\mathrm{d}}$.

(3) Since unconfined compression strength qu is a function of Gd and w, the dependency of qu on $\rho_{\mathrm{d}}$ and $\mathrm{w}$ could be directly evaluate from the plot of data results. The multiple correlation coefficient of the linear model of the scoria from this function is about 0.97 , which means the equation applied for scoria is accurate.

(4) The stiffness properties of scoria were quantified in terms of initial Young's modulus $\left(E_{0}\right)$ and secant modulus $\left(E_{50}\right)$. While some data scatters appear caused by the inhomogeneous of the samples, the effects of $\mathrm{w}$ and $\rho_{\mathrm{d}}$ to the stiffness of frozen scoria were observed. As well as initial Young's modulus E0, secant modulus $E_{50}$ of frozen scoria is increase with the increasing of $\mathrm{w}$ and $\rho_{\mathrm{d}}$.

\section{REFERENCES}

[1] Shoewu, O., Makanjuola, N. T., Akinyemi, L. A., \& Ogunlewe, A. O. (2015). Received Signal Strength in a Macrocell in Lagos Environs Using Finite Element Method. Review of Computer Engineering Research, 2(2), 47-64.

[2] Ma, W., and Chang, X., (2000): Effect of consolidating process on stress-strain behaviour of artificially frozen soil. Proceedings of the International Symposium on Ground freezing and Frost action in soils, Belgium. A. A Balkema, Rotterdam, pp. 151-154.

[3] Ono, T., (2002): Lateral deformation of freezing clay under triaxial stress condition using laser-measuring device, Cold regions science and technology, Vol 35, pp 45-54.

[4] Wang, D., Ma, W., Chang, X., (2004): Analyses of behaviour of stress-strain of frozen Lanzhou loess subjected to K0 consolidation, Cold regions science and technology, Vol 40, pp 19-29

[5] Agustian, Y., and Goto, Satoshi., (2008): "Strength and Deformation Characteristics of Scoria in Triaxial Compression at low Confining Stress," Soils and Foundations, Vol.48, No.1, pp.27-39

[6] Agustian, Y., and Goto, S., (2008): "Undrained Cyclic Shear Behaviour of Reconstituted Scoria Deposit," Soils and Foundations, Vol.48, No.6.

[7] Enokido, M., and Kameta, J., (1987): Influence of water content on compressive strength of frozen sands, Soils and Foundations, Vol. 27, No. 4, pp. 148-152

[8] Anma, So., (2007): Lahars and slush lahars on the slopes of Fuji volcano, Fuji Volcano, Yamanashi Institute of Environmental Sciences, pp. 285-301

[9] Jabarullah, N.H. \& Othman, R. (2018) Steam reforming of shale gas over $\mathrm{Al}_{2} \mathrm{O}_{3}$ supported $\mathrm{Ni}-\mathrm{Cu}$ nano-catalysts, 
Petroleum Science and Technology, DOI: 10.1080/10916466.2018.1547759.

[10] Jabarullah, N.H. (2019) Production of olefins from syngas over $\mathrm{Al}_{2} \mathrm{O}_{3}$ supported $\mathrm{Ni}$ and $\mathrm{Cu}$ nano-catalysts, Petroleum Science and Technology, DOI: 10.1080/10916466.2018.15 47758 